\title{
Differential Effects on Spatial Navigation of Immunotoxin-induced Cholinergic Lesions of the Medial Septal Area and Nucleus Basalis Magnocellularis
}

\author{
Joanne Berger-Sweeney, ${ }^{1}$ Stephan Heckers, ${ }^{2}$ Marek-Marsel Mesulam, ${ }^{2}$ Ronald G. Wiley, ${ }^{3}$ Douglas A. Lappi, ${ }^{4}$ \\ and Maitreyi Sharma' \\ 'Department of Biological Sciences, Wellesley College, Wellesley, Massachusetts 02181, ${ }^{2}$ Division of Neuroscience and \\ Behavioral Neurology, Beth Israel Hospital, and Harvard Medical School, Boston, Massachusetts 02215, ${ }^{3}$ Neurology \\ Service-127, DVAMC and Vanderbilt University, Nashville, Tennessee 37212, and ${ }^{4}$ The Whittier Institute, La Jolla, \\ California 92037
}

The effects on anatomy and behavior of a ribosomal inactivating protein (saporin) coupled to a monoclonal antibody against the low-affinity NGF receptor (NGFr) were examined. In adult rats, NGFr is expressed predominantly in cholinergic neurons of the medial septal area (MSA), diagonal band nuclei, and nucleus basalis magnocellularis (nBM), but also in noncholinergic cerebellar Purkinje cells.

Rats with immunotoxin injections to the MSA, nBM, and lateral ventricle were compared to controls on a spatial and cued reference memory task in the Morris maze. Toxin injections to the MSA slightly impaired the initial, but not asymptotic, phase of spatial navigation. Injections to the nBM impaired all phases of spatial navigation. Cued navigation, however, was not affected in either the MSA or nBM group. The ventricular injections severely affected spatial and cued navigation.

Acetylcholinesterase (AChE) histochemistry and NGFr and choline acetyltransferase immunohistochemistry revealed a loss of (1) almost all NGFr-positive cholinergic neurons in the MSA and AChE fibers in hippocampus (MSA group); (2) almost all NGFr neurons in the nBM, some in the MSA, most $A C h E$ fibers in neocortex and some in the hippocampus ( $B M$ group), and (3) almost all NGFr neurons in the MSA and nBM and their corresponding hippocampal and cortical AChE fibers (ventricular group). Cholinergic nBM projections to the amygdala were largely preserved in all groups.

The amount of cholinergic fiber loss in the cortex correlated modestly, but significantly, with the severity of impairment of the asymptotic phase of performance of the spatial task. An unambiguous interpretation of the anatomical locus of behavioral deficits was not possible because

Received Aug. 9, 1993; revised Dec. 27, 1993; accepted Feb. 2, 1994.

J.B.-S. thanks Dr. Urs Berger for critically reviewing the manuscript, Dr. Larry Baldwin for statistical consultation, and Ms. Karin Thomason for secretarial support. This work was supported, in part, by a Brachman-Hoffman small grant to J.B.-S. S.H. was supported by the Deutsche Forschungsgemeinschaft and the Nalional Alliance for Research on Schizophrenia and Depression. The work at the Whittier Institute was supported by grants to D.A.L. from the National Institutes of Health (DK-18811) and the Whittier Angiogenesis Research Program. M.S. was supported by an NSF undergraduate summer research grant (Bio 9200379). We also thank Drs. S. L. B. Hersh (ChAT), M. Bothwell (p75 NGF receptor), and $\mathrm{M}$. Celio (calbindin- $\mathrm{D}_{28 \mathrm{~K}}$ ) for antibodies.

Correspondence should be addressed to Joanne Berger-Sweeney at the above address.

Copyright (C) 1994 Society for Neuroscience $0270-6474 / 94 / 144507-13 \$ 05.00 / 0$ of damage to cholinergic striatal interneurons (nBM group) and to noncholinergic cerebellar Purkinje cells (ventricular group).

These data suggest that the cholinergic cortical system is critical to the performance of this spatial memory task. Cholinergic denervation of the hippocampus alone, however, is not sufficient to impair markedly performance of this task.

[Key words: 192 IgG saporin, immunotoxin lesion, nucleus basalis, medial septum, basal forebrain, water maze, rats]

Data from human and animal studies suggest that the cholinergic basal forebrain system is important in the neural circuitry of mnemonic processing (Perry et al., 1978; Bartus et al., 1982; Coyle et al., 1983; Ridley et al., 1986; Hohmann et al., 1988; Durkin, 1989; Olton et al., 1991a,b). Lesion studies focus attention on two anatomically discrete subdivisions within the basal forebrain, namely, the medial septal area (MSA), which includes the medial septum and diagonal band nuclei, and the substantia innominata/nucleus basalis magnocellularis (nBM). The cholinergic neurons of the MSA give rise to a dense innervation of the hippocampus, and the cholinergic neurons of the $\mathrm{nBM}$ give rise to a dense innervation of the cortex and amygdala (Lewis and Shute, 1967; Johnston et al., 1979; Mesulam et al., 1983; Rye et al., 1984; Saper, 1984; Amaral and Kurz, 1985; Wainer and Mesulam, 1990).

In rats, lesions of the MSA produced either electrolytically (Miyamoto et al., 1987; Kelsey and Landry, 1988; Fraser et al., 1991; M'Harzi and Jarrard, 1992), by local injections of ibotenate (Hepler et al., 1985; Hagan et al., 1988), or by intraventricular injections of AF64A (Messer et al., 1991) induce deficits on spatial memory tasks. These lesions decrease cholinergic markers in hippocampal targets up to $60 \%$. Similarly, deficits on spatial memory tasks have been observed in rats with nBM lesions produced by local injections of ibotenate (Dunnett, 1985; Whishaw et al., 1985; Kesner et al., 1987a; Miyamoto et al., 1987), and other neurotoxins (Hurlbut et al., 1987; Olton and Wenk, 1987; Wozniak et al., 1989; Dekker et al., 1991; Nabeshima et al., 1991). Reductions in cortical cholinergic markers up to $60 \%$ have been noted following these different nBM lesions. There is consensus in the literature that MSA and nBM lesions impair spatial more than cued memory; there is debate, however, concerning whether lesions in these two subsets of the basal forebrain produce spatial behavioral impairments that are 
qualitatively similar (Hepler et al., 1985) or qualitatively different (Miyamoto et al., 1987; Hagan et al., 1988).

There are serious limitations to all of these lesion studies because of the lack of specificity and completeness of the lesions. Electrolytic lesions damage mixed populations of neurons in the basal forebrain as well as fibers of passage (Dekker et al., 1991; Fibiger, 1991). Ibotenate, kainate, and quisqualate injections to the basal forebrain preserve fibers of passage but lack specificity for cholinergic neurons (Coyle and Schwartz, 1983; Dunnett et al., 1991). Local administration of AF64A, a cholinergic toxin, directly into the parenchyma produces considerable nonspecific tissue destruction (McGurk et al., 1987; Nakamura et al., 1992). Furthermore, these lesion methods rarely produce more than a $60 \%$ reduction in cholinergic markers in hippocampal and cortical targets even though $85-90 \%$ of cholinergic innervation to these targets is thought to originate in the basal forebrain (reviewed in Olton et al., 1991a; Dekker et al., 1992). Although attempts have been made to address the drawbacks of these lesion studies by administering cholinergic enhancing agents, such as muscarinic agonists (Murray and Fibiger, 1986), acetylcholinesterase (AChE) inhibitors (Murray and Fibiger, 1985; Mandel and Thal, 1988; Haroutunian et al., 1990; Sweeney et al., 1990), and nerve growth factor (NGF) to reverse lesioninduced deficits (Mandel et al., 1989), these results have not been conclusive (Fibiger, 1991).

Recently, the functional role of the cholinergic basal forebrain neurons in memory has been brought into question by a series of studies comparing the effects of quisqualate- and ibotenateinduced lesions (Dunnett et al., 1987; Robbins et al., 1989; Markowska et al., 1990; Connor et al., 1991). Quisqualate produces a larger reduction in cortical cholinergic markers than ibotenate following injection to the nBM. Quisqualate-induced lesions, however, produce less of a memory deficit, suggesting that noncholinergic neurons may play a critical role in previously noted behavioral deficits. Furthermore, quisqualate and ibotenate infusions into the nBM differentially affect projections to the amygdala; the former produces relatively little damage to amygdala projections, and the latter produces more substantial damage (Boegman et al., 1992).

A promising new tool has become available to target cholinergic basal forebrain neurons (Wiley, 1992). This tool exploits the fact that many cholinergic basal forebrain neurons express high levels of the low-affinity p75 NGF receptor (NGFr) relative to other cholinergic and noncholinergic neurons in nearby regions (Gage et al., 1989; Woolf et al., 1989; Yan and Johnson, 1989; Altar, 1991). Virtually all cholinergic MSA neurons and the majority of $\mathrm{nBM}$ neurons are NGFr positive. Other NGFrnegative cholinergic neurons in the $\mathrm{nBM}$, located primarily in the sublenticular substantia innominata, appear to provide the major cholinergic projection to the amygdala (Heckers et al., 1994). Additionally, some noncholinergic cerebellar Purkinje cells are NGFr positive.

When a monoclonal antibody to the $\mathrm{p} 75 \mathrm{NGF}$ receptor $(192$ $\mathrm{IgG}$ is coupled to the ribosomal-inactivating protein saporin, it selectively destroys neurons bearing NGFr in vivo in rats (Wiley et al., 1991; Book et al., 1992; Nilsson, 1992; Heckers et al., 1993). When this immunotoxin is injected into the ventricles, it produces decreases in ChAT activity from 85 to $90 \%$ in neocortex and hippocampus, while serotonin (5-HT), dopamine, and noradrenaline are relatively unaffected (Nilsson et al., 1992; Heckers et al., 1994). Intraventricular injections also spare NGFr-negative cholinergic neurons in the nBM, many of which project to the amygdala, as well as noncholinergic parvalbumin neurons in the MSA, and calbindin- $\mathrm{D}_{28 \mathrm{~K}}$ and NADPHdiaphorase neurons in the nBM (Heckers et al., 1994). In total, these studies suggest that in the adult rat $192 \mathrm{IgG}$ saporin is the most selective and complete toxin for destroying the cholinergic innervation of neocortex and hippocampus known to date.

The purpose of the present study is to examine the role of cholinergic basal forebrain structures in spatial memory using 192 IgG saporin. Four groups of rats were compared: (1) rats with $192 \mathrm{IgG}$ saporin injections into the MSA, (2) the nBM and (3) the lateral ventricle, and (4) saline-injected controls. Spatial and cued navigation tasks (Morris, 1981) were used to explore the quality of the behavioral performance and magnitude of any ensuing behavioral deficits. These tasks were chosen because of the sensitivity of the spatial task to lesions of the MSA and nBM and the relative lack of sensitivity of the cued navigation task to these same lesions (Dunnett et al., 1987; Hagan et al., 1988; Brandeis et al., 1989). Following the behavioral testing, the extent and specificity of the lesions were evaluated histologically using Nissl staining, AChE histochemistry, and p75 NGFr and ChAT immunocytochemistry. The specificity of the lesions was further evaluated using parvalbumin and calbindin- $D_{28 \mathrm{~K}} \mathrm{im}$ munohistochemistry. These markers were chosen because (1) noncholinergic neurons in the MSA, presumably GABAergic, express the calcium-binding protein parvalbumin (Freund, 1989), and (2) noncholinergic neurons, which are adjacent to cholinergic nBM neurons, express the calcium-binding protein calbindin- $\mathrm{D}_{28 \mathrm{~K}}$ (Heckers et al., 1994). Finally, the behavioral and anatomical results were correlated to determine if the amount of cholinergic fiber loss in the hippocampus and neocortex was associated with the severity of the behavioral deficits.

\section{Materials and Methods}

\section{Animals}

Thirty-eight male Sprague-Dawley rats weighing 250-300 gm were used in this experiment. The rats were housed together in pairs on a $12 \mathrm{hr} /$ $12 \mathrm{hr}$ light/dark cycle with food and water available ad libidum. All behavioral testing was conducted during the light cycle.

\section{Surgery}

All surgical procedures were conducted under aseptic conditions. Rats were weighed and sedated with acepromazine maleate $[0.3 \mathrm{ml}$, i.m. (10 $\mathrm{mg} / \mathrm{ml})]$. Twenty minutes later, the rats were given atropine sulfate $[0.25$ $\mathrm{ml}$, i.m. $(0.54 \mathrm{mg} / \mathrm{ml})]$ as a prophylactic and sodium pentobarbital [50 $\mathrm{mg} / \mathrm{kg}$, i.p. $(64.8 \mathrm{mg} / \mathrm{ml})]$ as an anesthetic. An anesthetized rat was placed in the stereotaxic apparatus, a hole was drilled in the skull, and a syringe filled with either saline or a $192 \mathrm{IgG}$ saporin solution $(0.42$ $\mathrm{mg} / \mathrm{ml}$ ) was lowered stereotaxically to one of three locations. The preparation of $192 \mathrm{IgG}$ saporin is described elsewhere (Wiley and Lappi, in press). The toxin was injected over $5 \mathrm{~min}$, and the needle was left in place for an additional $5 \mathrm{~min}$. Coordinates for the lesions were based on the atlas of Paxinos and Watson (1986).

Septal injections. The syringe was lowered at a $15^{\circ}$ angle from the surface of the brain to the MSA to avoid puncturing the central sinus. A single injection was made at coordinates $\mathrm{AP}+0.6, \mathrm{ML}-1.5$, and DV -6.7 relative to bregma. Either $0.3 \mu \mathrm{l}$ of $192 \mathrm{IgG}$ saporin $(n=8$ rats) or $0.3 \mu$ l of saline $(n=6)$ was injected into the septal nuclei.

Substantia innominata/nucleus basalis magnocellularis injections. Coordinates were based on those described by Wenk et al. (1984) to produce the maximal cortical cholinergic loss. A pair of injections were made at coordinates $\mathrm{AP}-0.9, \mathrm{ML} \pm 2.8$, and $\mathrm{DV}-7.2$ relative to bregma. Either $0.3 \mu \mathrm{l}$ of $192 \mathrm{IgG}$ saporin $(n=5)$ or $0.3 \mu \mathrm{l}$ of saline $(n$ $=3$ ) was injected into each side of the $n B M$ region.

Ventricular injections. A single injection into the right lateral ventricle was made at coordinates $\mathrm{AP}-1.0, \mathrm{ML}+1.5$, and $\mathrm{DV}-4.5$ relative to bregma. Eight microliters of either $192 \operatorname{IgG}$ saporin $(n-8)$ or saline $(n$ $=9$ ) were injected. 


\section{Behavioral apparatus}

The pool used for spatial navigation trials was $180 \mathrm{~cm}$ in diameter and constructed of black acrylic. The pool was located in a room surrounded by cues external to the maze, such as geometric paintings and plumbing fixtures, which could be used by the rat to guide its navigation in the pool. The pretraining pool was a $103 \mathrm{~cm}$ diameter metal ring that could be placed inside the larger pool. The pool was filled with $21-23^{\circ} \mathrm{C}$ water and contained a square clear acrylic platform $(6 \times 6 \mathrm{~cm})$ with ridges on the top to enable the rat to climb more easily from the water. The platform was secured $25 \mathrm{~cm}$ from the edge of the pool in the NE quadrant (see below). For the spatial navigation trials, the platform was submerged $4 \mathrm{~cm}$ below the surface of the water. For the cued navigation trials, the platform was $4 \mathrm{~cm}$ above the surface of the water and covered with a metal plate. The rat's movement in the pool was registered using a computer based video tracking system (HVS Image, Hampton, England).

\section{Behavioral procedures}

Habituation and pretraining. Two days after surgery, each rat was habituated to the experimenter in its home cage. Habituation consisted of petting and handling each rat for 5-10 min each day for 6 or 7 consecutive days. Behavioral testing began with $2 \mathrm{~d}$ of spatial navigation pretraining. The smaller ring was placed in the pool. On the first trial, the rat was placed by hand on the platform for $25 \mathrm{sec}$. The rat was then placed in the water first very close and then continually farther away from the platform. Each time the rat was allowed to climb onto the platform and rest for $10 \mathrm{sec}$ before being placed back into the water. Each rat had 10 pretraining trials per day.

Spatial navigation (invisible platform) and probe trials. For the training trials, the pretraining ring was removed. Four equally spaced points around the edge of the pool were used as start positions and were arbitrarily designated as N, S, E, and W. Each rat was given four trials/ day, one from each of the four starting points. The rat was placed into the water facing the edge of the pool, but not touching it; the rat then had a maximum of $120 \mathrm{sec}$ to find and get onto the platform. If the rat did not find the platform in the maximum time allotted, it was placed on the platform by the experimenter. Latency and path length, percentage of time in each quadrant and zone of the pool were monitored. Swim speeds were calculated from the latency and path length measurements. At the end of the four trials, the rat was removed from the pool, dried and returned to its home cage. The spatial task was conducted for 6 consecutive days.

The spatial trials were followed by a single probe trial. In the probe trial, the platform was removed. Each rat was started from the $\mathrm{N}$ position and its movement was tracked for a $30 \mathrm{sec}$ period.

Cued navigation (visible platform with platform relocation) trials. Two days after the probe trial, cued testing began. In this task, the testing protocol was similar to that used during the invisible platform trials except that the platform was made visible. On the first day of the cued trial, the visible platform was in the same quadrant that was used as the training quadrant in the spatial task. On the subsequent days, the platform was relocated pseudorandomly to different quadrants of the pool-each new day, a new position. The rat was placed in the pool, facing the wall, and was given a maximum of $120 \mathrm{sec}$ to find and get onto the platform. The rat performed four trials/day, one from each starting position, for 4 consecutive days.

\section{Histological procedures}

At the end of behavioral testing, each rat was given an overdose of sodium pentobarbital. The rat was then perfused transcardially with $50-100 \mathrm{ml}$ of $0.9 \%$ saline, followed by either $150 \mathrm{ml}$ of $4 \%$ paraformaldehyde in $0.1 \mathrm{~m}$ phosphate buffer ( $\mathrm{pH} 7.4$ ) or $150 \mathrm{ml}$ of $4 \%$ paraformaldehyde with $0.5 \%$ glutaraldehyde and $15 \%$ saturated picric acid solution in $0.1 \mathrm{M}$ phosphate buffer $(\mathrm{pH} 7.4)$ for $20 \mathrm{~min}$, followed by $100 \mathrm{ml}$ of $10 \%$ sucrose solution. The brain was then removed and immersed in a $30 \%$ sucrose solution and stored overnight at $4{ }^{\circ} \mathrm{C} . \mathrm{Co}-$ ronal sections $(40 \mu \mathrm{m})$ were cut on a freezing microtome and stored at $4^{\circ} \mathrm{C}$ in a $0.1 \mathrm{M}$ phosphate buffer solution containing $0.02 \%$ sodium azide. Staining procedures have been previously described (Heckers et al., 1994) and are summarized here.

Nissl stains. One series of sections per rat was mounted on chromalum-subbed slides, air dried, and stained in a $0.1 \%$ cresyl violet solution for $5 \mathrm{~min}$.

Acetylcholinesterase histochemistry. One series of sections per rat was mounted on chromalum-subbed slides, air dried, and stained for AChE using the Tago modification of the Karnovsky-Roots histochemical procedure (Tago et al., 1986; Mesulam et al., 1987).

Immunohistochemistry. Staining was carried out using the avidinbiotin $\mathrm{ABC}$ procedure (Hsu et al., 1981) with monoclonal antibodies against purified p75 NGF receptors (1:500) and the calcium-binding protein parvalbumin purified from carp muscle $(1: 2000)$ (Sigma, St. Louis, MO) and polyclonal antibodies against human placental ChAT $(1: 1000)$ and the vitamin $\mathrm{D}$-dependent calcium-binding protein calbindin- $D_{2 я к}$ (1:5000; see acknowledgment for sources).

Analysis. Sections were examined using bright-field microscopy. The examiner was blind to the behavioral results. The extent of the cholinergic basal forebrain lesion was examined throughout the forebrain in serial, adjacent sections stained for AChE, ChAT, and NGFr. The evaluator then rated the relative amount of remaining AChE-positive fibers in the cortex and hippocampus in the different lesion groups as compared to controls using magnitude scaling, an interval scaling procedure to provide a numeric estimation of fiber density (Stevens, 1975; Lodge, 1981). Scores between 1 and 5 were given to rats that exhibited almost complete loss of cortical and hippocampal AChE-positive fibers. Scores between 6 and 14 were given to rats that had substantial cholinergic loss in the cortex with moderate loss in the hippocampus. Scores between 15 and 20 were given to rats with preservation of the cortical cholinergic fibers and the loss was restricted to the hippocampus and medial cortical areas (cingulate and retrosplenial cortex). Lower scores were therefore associated with more substantial losses of cholinergic fibers. These histological ratings were subsequently correlated with the scores from the behavioral tasks.

\section{Data analysis and statistics}

The spatial and cued behavioral data were analyzed using repeatedmeasures analysis of variance (ANOVA); the repeated measures were the different days of testing for a given rat. Fisher's protected least significant differences (PLSDs) were used, post hoc, to compare pairwise means between the lesion and control groups. The probe trial data were analyzed using factoral ANOVAs. Finally, stepwise linear regressions were carried out to determine if the loss of cholinergic staining in the hippocampus and cortex correlated with performance on the behavioral tasks.

\section{Results}

Rats with saline injections into the MSA, nBM, or lateral ventricle did not differ significantly on any of the behavioral measures analyzed. These data were therefore pooled and all of these rats are referred to as controls $(n=18)$. Previous studies have shown that control/vehicle injections of $192 \mathrm{IgG}$ uncoupled from saporin do not produce neurotoxicity (Wiley et al., 1991) or alterations in spatial navigation (Nilsson et al., 1992) in the rat. The present study contained three other groups: (1) rats with $192 \mathrm{IgG}$ saporin injected into the MSA (the septal group, $n=$ $8)$, (2) rats with $192 \mathrm{IgG}$ saporin injected into the $\mathrm{nBM}$ region (the nBM group, $n=5$ ), and (3) rats with $192 \lg G$ saporin injected into the lateral ventricle (the ventricular group, $n=8$ ).

\section{Survival, general health, and motility}

No rats in the ventricular or nBM groups died after the surgery. One control and one septal rat died during the course of the study, on days 3 and 14, respectively. None of the rats in this study, either saline injected or $192 \mathrm{IgG}$ saporin injected, showed overt behavioral signs of seizure activity.

The postoperative health of all of the 192 IgG saporin-injected rats was poorer than saline-injected controls, as seen in consistently lower mean weights of the former group during the first week of behavioral testing (Table 1). These differences were highly significant $[F(3,66)=4.6, p<0.01]$. Post hoc analysis revealed that the ventricular group had significantly lower mean weights than controls on all days during the invisible platform 


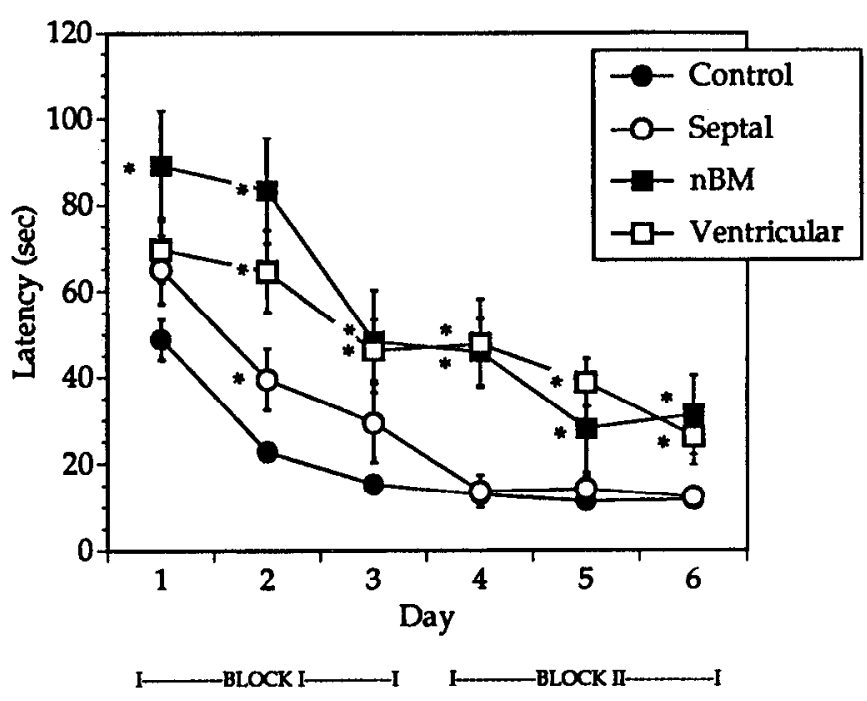

Figure 1. Mean latencies for the spatial navigation task. Performance of the groups \pm SEM (error bars) over the $6 \mathrm{~d}$ of testing is shown. Block $I$ refers to the first $3 \mathrm{~d}$ of the trial when latencies were steadily decreasing. Block II refers to the last $3 \mathrm{~d}$, when most rats had reached asymptotic performance levels. Repeated-measures ANOVAs revealed significant differences by lesion status, days and interaction effect. *, latencies that differed significantly from controls in post hoc analyses (PLSD).

testing. The septal group exhibitcd significantly lower mean weights on days $5 / 6$ and $7 / 8$.

The ventricular group was considerably more passive than the control, septal, or nBM group, rarely offering resistance during habituation and handling. The ventricular group also exhibited motility problems, frequently dragging their hindpaws behind them when walking. Three rats in the ventricular group had dramatic enough motor impairments that they were not able to swim 1 week after surgery and hence could not perform the navigation tasks. These rats were analyzed histologically but they were not included in any of the subsequent behavior analyses.

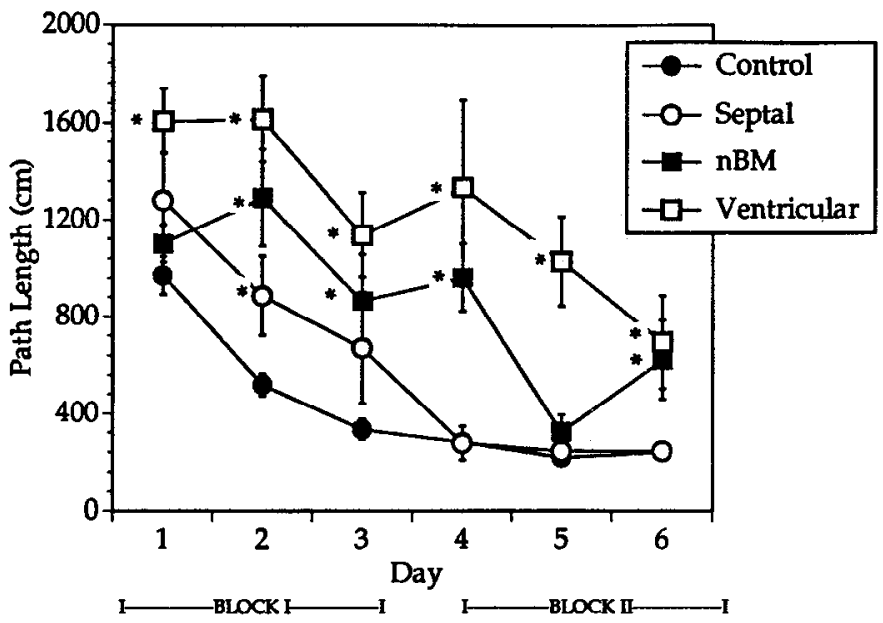

Figure 2. Mean path lengths for the spatial navigation task. Performance of the groups \pm SEM (error bars) over the $6 \mathrm{~d}$ of testing is shown. Block $I$ refers to the first $3 \mathrm{~d}$ of the trial when latencies were steadily decreasing. Block $I I$ refers to the last $3 \mathrm{~d}$, when most rats had reached asymptotic performance levels. Repeated-measures ANOVAs revealed significant differences by lesion status, days and interaction effect. *, path lengths that differed significantly from controls in post hoc analyses (PLSD).

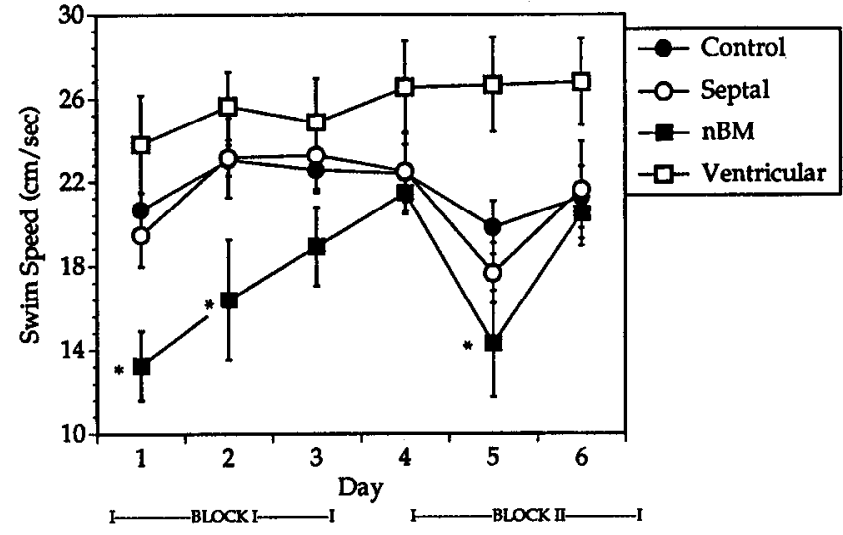

Figure 3. Average swim speeds on the spatial navigation task. Swim speeds of the groups \pm SEM (error bars) over the $6 \mathrm{~d}$ of the spatial task are shown. ANOVAs revealed that the groups differed significantly by group and by day. ${ }^{*}$, swim speeds that differed significantly from controls in post hoc analyses (PLSD).

Acquisition and performance on the spatial navigation (invisible platform) task. When initially placed in the tank, all of the rats swam primarily around the perimeter of the tank. Occasionally, the rats would traverse the tank and eventually bump into and climb on the invisible platform. The performance of all of the rats improved steadily within a session of four trials and between successive days.

Latency. Mean escape latencies to locate the platform on successive days of the spatial navigation task are shown in Figure 1. Mean escape latencies were high on the first day for all four groups; all rats, however, showed a marked reduction in latencies over the first $3 \mathrm{~d}$. This period of marked decrease is referred to as block I. Mean latencies flattened out between days 4 and 6 , representing asymptotic performance (block II). Overall mean escape latencies were highest in the nBM group followed by the ventricular group, septal group, and controls; this pattern was true on all $6 \mathrm{~d}$ of the invisible platform trials. Repeated-measures ANOVAs revealed highly significant differences by (1) lesion status $[F(3,31)=18.7, p<0.001]$, (2) days $[F(5,55)=$ $64.04, p<0.001]$, and (3) interaction effects $(F=3.01$ with 14 df, $p<0.01$ ). Post hoc analyses (Fisher PLSD) revealed that mean latencies for the septal group were significantly higher than controls on day 2; latencies for the nBM group were significantly higher than controls on all $6 \mathrm{~d}$; latencies for the ventricular groups were significantly higher than controls on days $2-6$. When a separate ANOVA was carried out on the control and septal groups alone, highly significant differences were apparent by

Table 1. Mean weights during invisible platform testing

Days of invisible platform testing

\begin{tabular}{lllll}
\cline { 2 - 5 } Group & $1-2$ & $3-4$ & $5-6$ & $7-8$ \\
\hline Control & $343 \pm 4$ & $369 \pm 4$ & $374 \pm 3$ & $378 \pm 3$ \\
Septal & $329 \pm 8$ & ND & $355 \pm 6^{*}$ & $357 \pm 6^{*}$ \\
nBM & $330 \pm 16$ & ND & $365 \pm 10$ & $372 \pm 10$ \\
Ventricular & $308 \pm 4^{*}$ & $332 \pm 5^{* *}$ & $342 \pm 4^{*}$ & $349 \pm 3^{*}$
\end{tabular}

ND, no data available.

* Significant Fisher PLSD values $p<0.05$ as compared to controls.

** Significant differences on a $t$ test. 


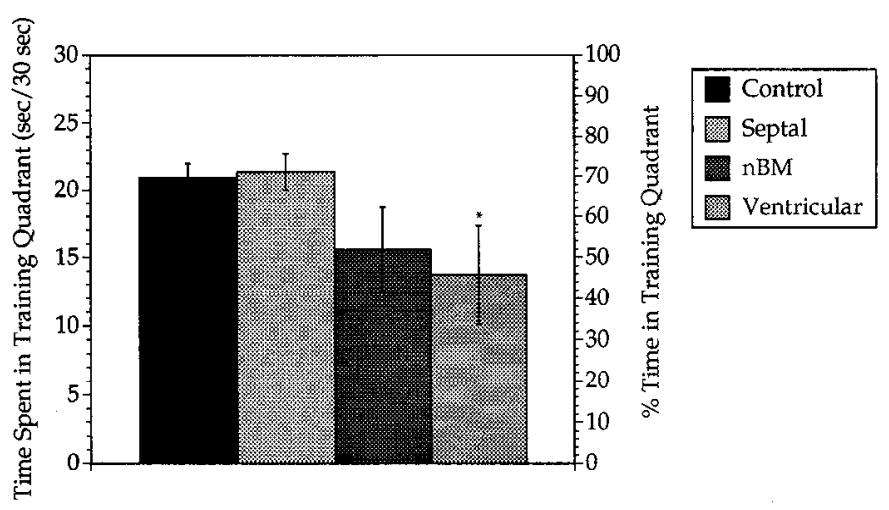

Figure 4. Performance on the probe trial. The time spent in the training quadrant out of $30 \mathrm{sec}$ (on left axis) and the percentage of time in the training quadrant (on the right axis) \pm SEM (error bars) for the groups are shown. ${ }^{*}$, significant differences from control group (ANOVA).

group $[F(1,23)=8.2, p<0.01]$ and by day $[F(5,23)=45.6, p$ $<0.001]$. A small, but significant, interaction effect was also noted $[F(5,115)=2.33, p<0.05]$.

Path length. Mean path length showed a similar overall pattern to that of mean latencies; all groups started of high and then decreased markedly within the first $3 \mathrm{~d}$ (block I; see Fig. 2 ). For path lengths, the highest values were exhibited by the ventricular group followed by the nBM group, the septal group, and controls. Repeated-measures ANOVA revealed significant differences by lesion status $[F(3,31)=22.2, p<0.001]$, successive days $[F(5,155)=46.9, p<0.001]$, and interaction effect $[F(15,115)=3.1, p<0.01]$. Post hoc analyses revealed that the path lengths for the septal group were significantly longer than controls on day 2 ; those of the $\mathrm{nBM}$ group were significantly longer than controls on days $2,3,4$, and 6 ; those of the ventricular group were significantly longer than controls on all $6 \mathrm{~d}$.

Swim speed. The relative difference in the order of overall performance between the latency and path length data was due primarily to differences in swim speed among the groups. The nBM group had the highest latencies, but the ventricular group had the longest path lengths. The nBM group was swimming significantly slower on days 1,2 , and 5 than the control and septal groups. The ventricular group was swimming faster than the other groups; this difference reached significance on day 5 . Highly significant differences were seen in swim speed by group $[F(3,31)=4.6, p<0.01]$ and by day $[F(5,155)=6.0, p<0.001]$ (see Fig. 3).

\section{Performance on the probe trial}

Qualitative analysis of the probe trial revealed that control and septal rats were spending most of their time in the training quadrant where the platform had been. The nBM group was swimming around the perimeter of the pool, not particularly directed toward the training quadrant. The ventricular group tended to swim in either clockwise or counterclockwise circles in the pool perimeter. These observations were confirmed by the quantitative analysis of probe trial paths. Control rats spent $21.0 \pm 1 \mathrm{sec}$ out of $30 \mathrm{sec}$ ( $70 \%$ of the time) in the training quadrant (Fig. 4). The septal rats spent $21.3 \pm 1 \mathrm{sec}(71 \%)$, the nBM group $15.5 \pm 3 \mathrm{sec}(52 \%)$, and the ventricular group 13.7 $\pm 4 \sec (46 \%)$ in the training quadrant (Fig. 4). These data were significantly different by group $[F(3,31)=3.68, p<0.05]$. Post hoc analyses revealed that the ventricular group spent signifi-

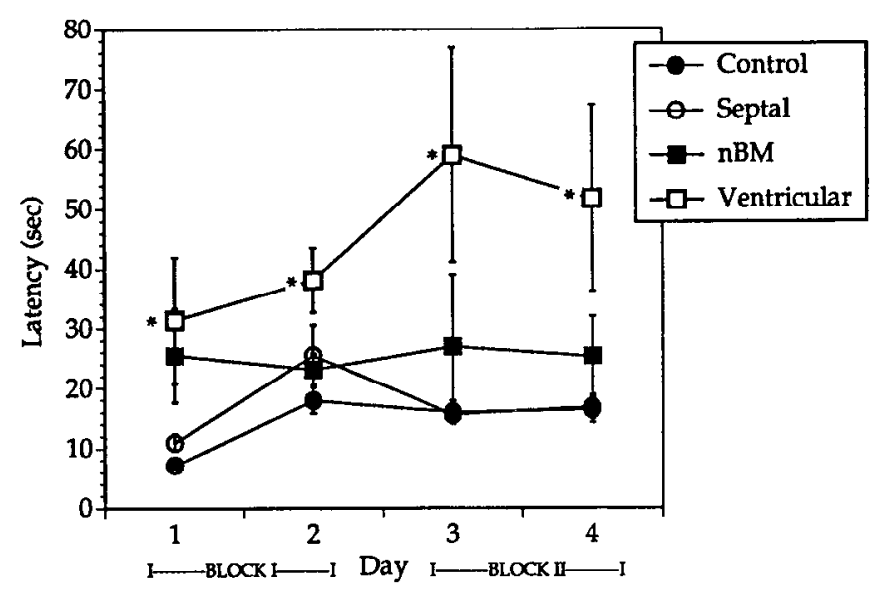

Figure 5. Mean latencies for the cued navigation task. Performance of the groups \pm SEM (error bars) over the $4 \mathrm{~d}$ of testing is shown. On day 1 , the cued platform is in the same position as it was during the spatial trials; on days $2-4$ the position of the platform changes. Block $I$ refers to the first $2 \mathrm{~d}$ of the trial when latencies were varying. Block $I I$ refers to the last $2 \mathrm{~d}$, when most rats had reached asymptotic performance levels. Repeated-measures ANOVAs revealed significant differences by lesion status and days. *, latencies that differed significantly from controls in post hoc analyses (PLSD).

cantly less time in the training quadrant than the control and septal rats. Additionally, the ventricular rats exhibited a longer path length than controls $(691 \pm 90 \mathrm{~cm}$ vs $596 \pm 46 \mathrm{~cm})$; these differences, however, did not reach statistical significance.

\section{Performance on cued task}

On the first day of the cued task, the platform was in the spatial training quadrant, but was now visiblc (scc Matcrials and Mcthods for further details). When placed in the tank, the control and septal groups headed immediately for the platform in the cued location. The nBM and ventricular groups swam throughout the tank and eventually bumped into the platform. On each successive day, the cued platform was moved to a different quadrant of the pool. When the platform location was moved, the control and septal rats initially headed to the place where the platform had been located and swam in the vicinity of the previously correct location before exploring the rest of the tank. Over the course of the trials, the rats learned to approach the visible platform. The $\mathrm{nBM}$ and ventricular groups did not show this preference for the previously correct location, but over the course of the visible trials, the former learned to approach the visible platform while the latter did not.

Latency. There were significant differences in the latencies of the cued trials by group $[F(3,30)=18.8, p<0.01]$ and by day $[F(3,9)=3.9, p<0.05]$. Significant interaction effects, however, were not noted. Post hoc analyses revealed that the significant differences were due to the ventricular group performing significantly worse than the control, septal, and nBM groups on all $4 \mathrm{~d}$ of testing (see Fig. 5). On day 1 the control and septal groups performed similarly (7.1 and 11.0 mean sec, respectively). The nBM and ventricular groups took significantly longer to find the cued platform (in the original spatial training quadrant). Their scores were 25.5 and $31.4 \mathrm{sec}$, respectively. On day 2 , when the cued platform was moved to a new position, all of the groups except the nBM group took longer to find the visible platform than on day 1 . On all subsequent days, the control, septal, and nBM groups performed similarly; however, 


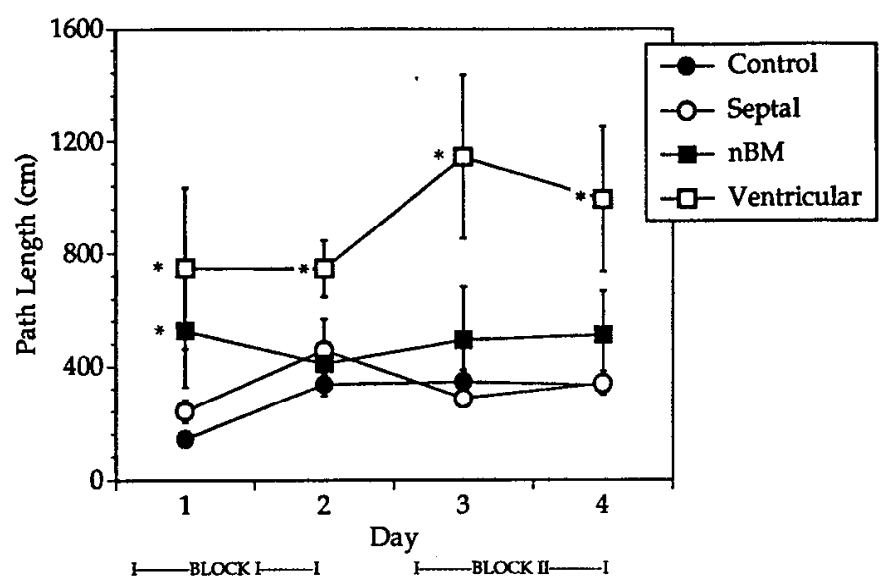

Figure 6. Mean path lengths for the cued navigation task. Performance of the groups \pm SEM (error bars) over the $4 \mathrm{~d}$ of testing is shown. On day 1 , the cued platform is in the same position as it was during the spatial trials; on days $2-4$ the position of the platform changes. Block $I$ refers to the first $2 \mathrm{~d}$ of the trial when latencies were varying. Block $I I$ refers to the last $2 \mathrm{~d}$, when most rats had reached asymptotic performance levels. Repeated-measures ANOVAs revealed significant differences by lesion status. ${ }^{*}$, path lengths that differed significantly from controls in post hoc analyses (PLSD).

the ventricular groups took significantly longer to find the cued platform on all days of testing.

Path length and swim speeds. The path length data showed a very similar pattern to that of the mean latencies (see Fig. 6), with the ventricular group having a significantly longer path length than the control, septal, and nBM groups $(F-23.41$ with $3,30 \mathrm{df}, p<0.01)$. No significant differences by day or interaction effects were noted. Analysis of swim speeds revealed no significant differences among the groups in this phase of the task $[F(3,30)=0.29, p \gg 0.05]$, in contrast to the findings during the spatial trials.

Persevering. On the first day of the cued trials, the control and septal groups spent more than $60 \%$ of the time in the quadrant with the visible platform, which was also the spatial training quadrant (see Fig. 7). Both groups spent successively less time in this original training quadrant on different days of the trial. In the $\mathrm{nBM}$ and ventricular groups, there was virtually no change in the percentage of time spent in the original training quadrant over trials.

\section{Histology}

Controls. The needle tracks in the controls could be readily identified in Nissl-stained sections. The saline injections into the MSA and bilaterally into the $\mathrm{nBM}$ resulted in small, but identifiable, amounts of gliosis in these regions. The intraventricular injections did not lead to gliosis in either area. NGFrpositive neurons throughout the basal forebrain, parvalbuminpositive neurons in the MSA, and calbindin-positive neurons in the nBM exhibited normal staining patterns following saline injections. The ChAT-positive neurons in the MSA and nBM were largely unaltered following saline injections (see Fig. $8 A, B$ ).

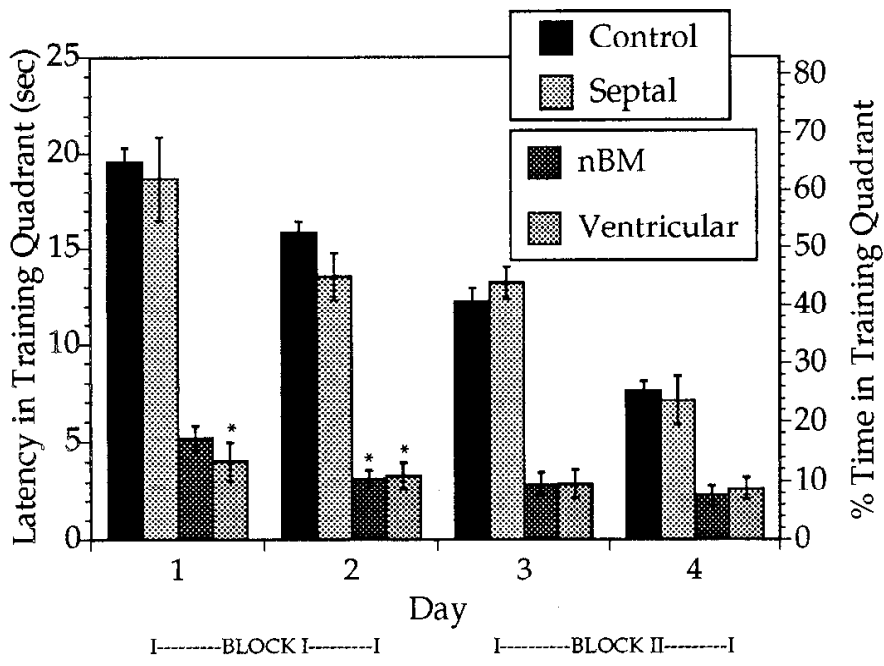

Figure 7. Time spent in the original spatial training quadrant during the cued navigation task. Latency (left axis) and percentage of time (right axis) in the training quadrant over the days of the cued trial \pm SEM (error bars) are shown. *, values that are significantly different from controls on a given day.

Similarly, the cholinergic fibers in the targets of these neurons, namely, the hippocampus, cortex, olfactory bulb, and amygdala, were not altered following these injections (see Fig. 9A,B).

Septal group. The injection track in the medial septum could be readily identified in the Nissl-stained sections. Gliosis in the area surrounding the injection was noticeable. The injections directly into the MSA resulted in an almost complete loss of NGFr-positive neurons in this region, but preservation of NGFrpositive neurons in the nBM. Similarly, ChAT-positive cells in this region were almost completely lost (see Fig. $8 \mathrm{C}$ ), but ChATpositive neurons in the nBM were preserved (see Fig. $8 D$ ). The immunotoxin injections, while producing a widespread loss of NGFr- and ChAT-positive neurons throughout the MSA, did not alter immunoreactivity for parvalbumin-positive neurons in the immediate vicinity of the needle track.

There was a nearly complete loss of AChE fiber-staining bilaterally in the hippocampus (see Fig. 9C). AChE fiber staining was preserved, however, throughout most of the cortical mantle (see Fig. 9D) except for medial and directly adjacent cortical areas (cingulate cortex, retrosplenial cortex, frontal cortex, forelimb and hindlimb areas, and occipital cortex).

$n B M$ group. Bilateral needle tracks in the substantia innominata/nucleus basalis magnocellularis complex were visible in the Nissl-stained sections. Gliosis extended throughout the complex. There was a virtually complete loss of NGFr-positive neurons throughout the $\mathrm{nBM}$. Additionally, there was a mild to moderate loss of NGFr-positive neurons in the MSA. Similarly, there was a mild to moderate loss of ChAT-positive neurons in the MSA (see Fig. $8 E$ ) and a dramatic loss of ChAT-positive neurons in the nBM (see Fig. $8 F$ ). A number of ChAT-positive neurons in the nBM were spared. These neurons do not express p75 NGFr, are located primarily in the sublenticular substantia innominata, and appear to provide the major cholinergic projections to the amygdala (Heckers et al., 1994). Additionally,

Figure 8. Differences in the distribution of ChAT-positive neurons in the basal forebrain after injections of saline or 192 IgG saporin: cholinergic neurons of the medial septum $(C h 1)$ and vertical limb of the diagonal band (Ch2) (left column) and the nucleus basalis (Ch4) (right column) in a salinc-trcatcd rat $(A, B)$ and in rats after $192 \mathrm{IgG}$ saporin injections into the medial septal area $(C, D)$, the substantia innominata $(E, F)$, and the cerebral ventricle $(G, H)$. Scale bar, $0.2 \mathrm{~mm}$. 

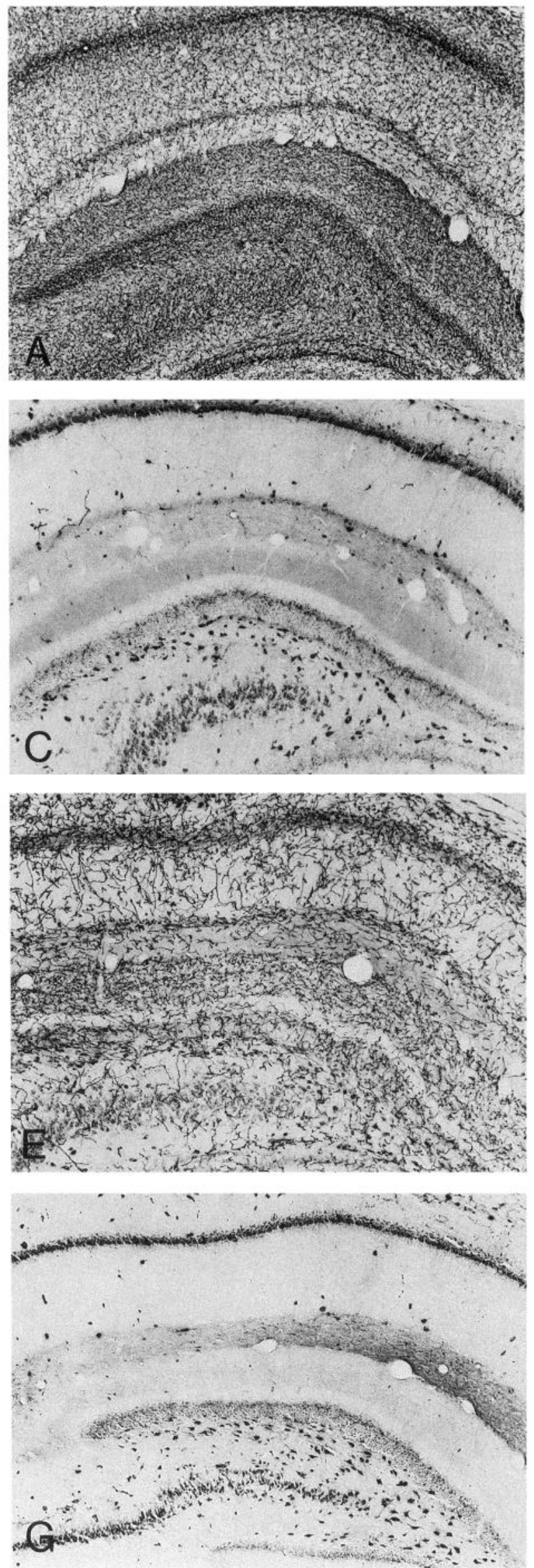
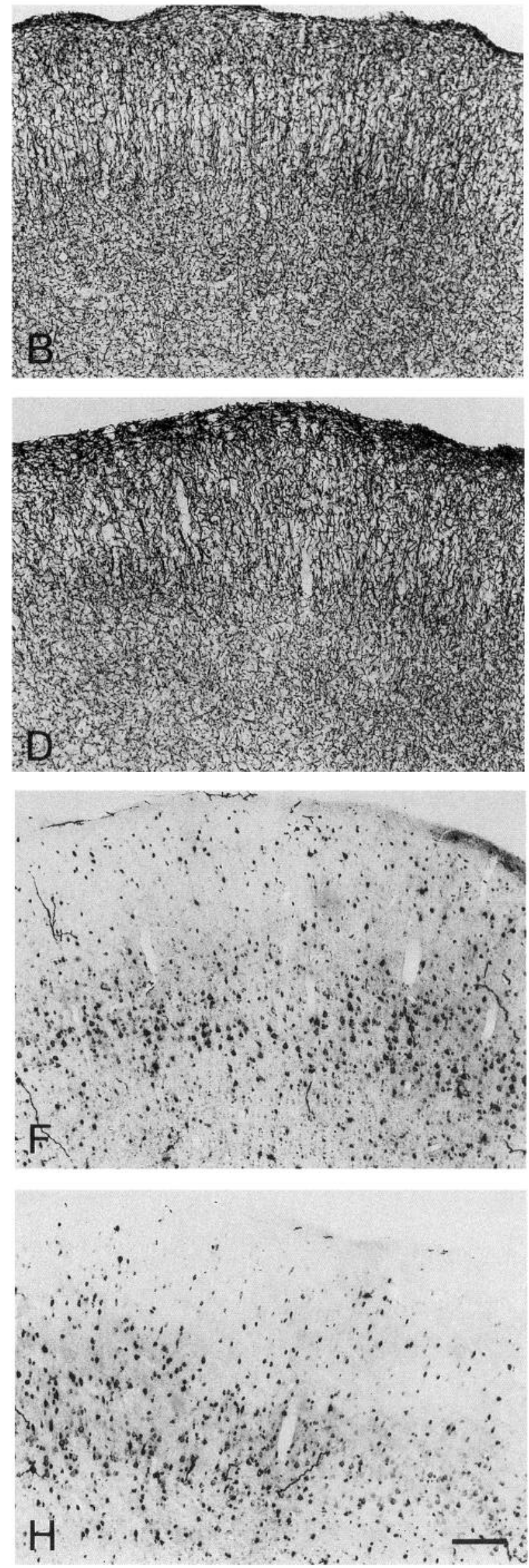

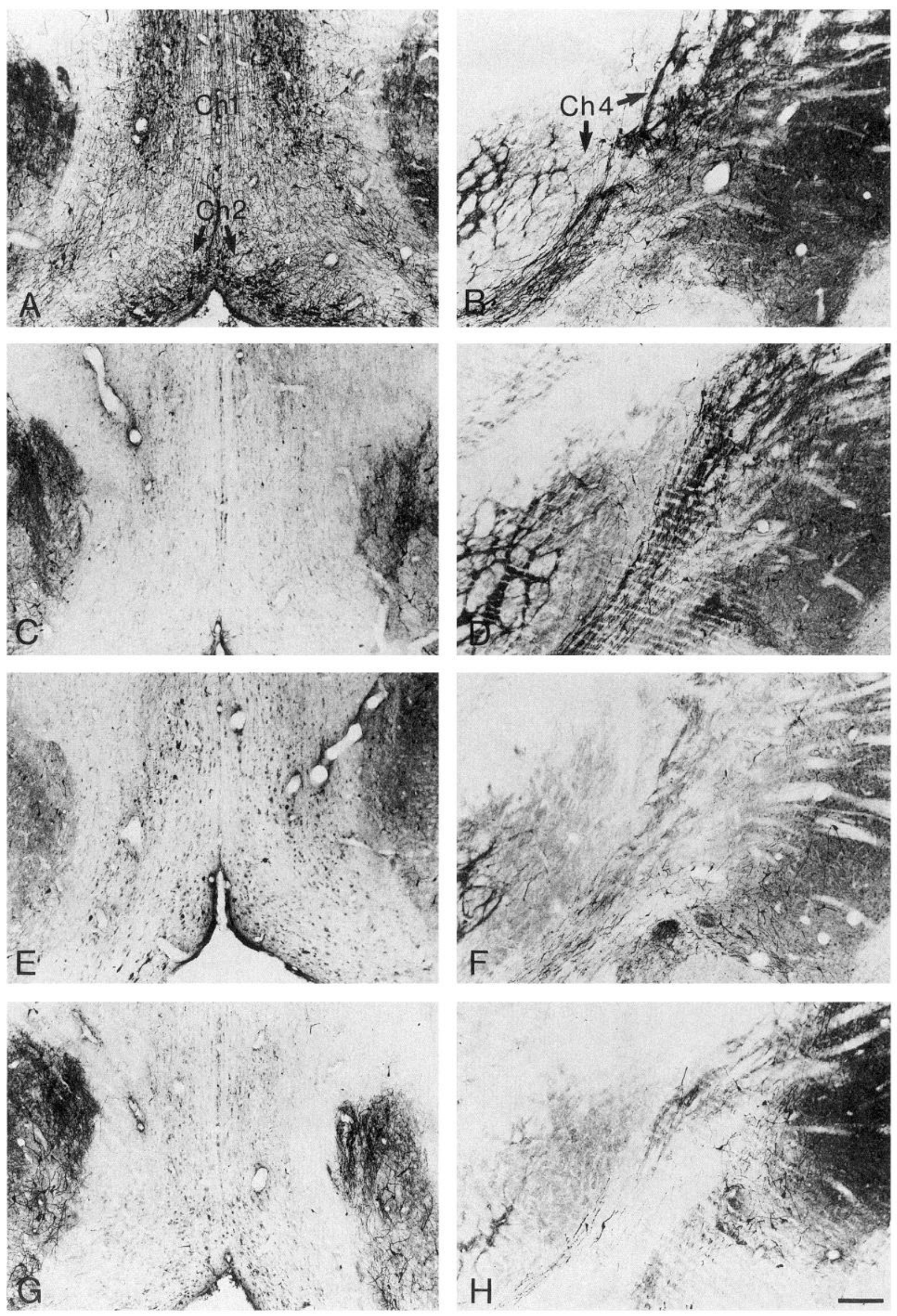
there was damage to cholinergic striatal interneurons adjacent to the nBM (described more fully in Heckers et al., 1994).

The immunotoxin injections, while inducing a widespread loss of ChAT-positive nBM neurons, did not change the immunoreactivity for calbindin- $\mathrm{D}_{28 \mathrm{~K}}$ in neurons adjacent to the nBM.

AChE fiber staining was mildly to moderately decreased in the hippocampus (see Fig. $9 E$ ) and dramatically reduced in frontal, temporal, parietal, and occipital cortices (see Fig. 9F). $\Lambda \mathrm{ChE}$-positive fibers in the amygdala were not substantially decreased by these injections.

Ventricular group. The ventricular injections induced gliosis in the MSA and nBM. There was an almost complete loss of NGFr immunoreactivity in the MSA and bilaterally in the nBM. Additionally, an almost complete loss of the ChAT-positive neurons was apparent in the MSA and a dramatic loss of ChATpositive neurons was seen in the nBM (see Fig. $8 G, I I$ ). Similar to the intraparenchymal injections, ChAT-positive neurons in the sublenticular substantia innominata, presumably projecting to the amygdala, were largely preserved. ChAT-positive neurons in the mesencephalic trigeminal nucleus, raphe, and striatum were also not decreased following the lesion.

Noncholinergic parvalbumin-positive neurons in the MSA and calbindin $D_{28 \mathrm{~K}}$-positive neurons lateral to the nBM exhibited staining patterns similar to controls.

A virtually complete loss of AChE fibers was observed bilaterally in the hippocampus (see Fig. 9G) and the cortical mantle (see Fig. 9H). Significant loss of noncholinergic NGFr-positive Purkinje cells in the cerebellum was also apparent (described more fully in Heckers et al., 1994). This loss was particularly dramatic in the three rats that were unable to perform the navigation task because of motoric impairments.

\section{Correlations between anatomy and behavior}

In order to determine whether there was a correlation between the amount of cholinergic loss (as determined anatomically) and behavioral measures, simple regression analyses were conducted (see Materials and Methods). The analyses were applied to all rats from the septal, nBM, and ventricular groups that performed the full sequence of tests $(n=17)$. We chose to perform this analysis on the combined groups (1) to increase the power of the analysis by adding together the number of rats in the separate groups and (2) because there were varying amounts of cholinergic cortical fiber losses in the different groups. Behavioral performance was divided into two blocks of trials-block I when rats were improving daily and block II when virtually all rats had reached asymptotic performances. The probe trials were analyzed separately.

Histology scores were modestly, but significantly, correlated with spatial and cued latencies and path lengths in block II and cued latency in block I (Table 2). In general, more extensive losses of cortical cholinergic fibers were associated with more impaired navigation performance. Preservation of cholinergic fibers in the cortex with substantial loss of cholinergic hippocampal fibers (high histology scores; see Materials and Methods) was associated with short spatial and cued latencies and path
Table 2. Correlations between cholinergic loss and rats' performance on different aspects of the behavioral task

\begin{tabular}{ll} 
Behavioral measures & $\begin{array}{l}\text { Correlation } \\
\text { coefficient }\left(\boldsymbol{r}^{2}\right)\end{array}$ \\
\hline Significant correlations & \\
Spatial latency (block II) & $-0.272^{*}$ \\
Spatial path length (block II) & $-0.426^{* *}$ \\
Probe trial time & $+0.335^{* *}$ \\
Cued latency (block I) & $-0.288^{*}$ \\
Cued latency (block II) & $-0.272^{*}$ \\
Cued path length (block II) & $-0.488^{* *}$ \\
Nonsignificant correlations & \\
Spatial latency (block I) & -0.133 \\
Spatial path length (block I) & -0.126 \\
Cued path length (block I) & -0.216 \\
\hline
\end{tabular}

* Significant at $p<0.05$.

** Significant at $p<0.01$.

lengths (good navigation performance). Extensive loss of cholinergic fibers in the cortex with mild to moderate loss of hippocampal fibers (moderate histology scores) was associated with moderate navigation performance. Finally, a virtually complete loss of cholinergic fibers in cortex and hippocampus (low histology scores) was associated with poor navigation performance. Histology scores were also correlated significantly with probe trial times. The most significant cortical fiber losses were associated with the shortest amount of time spent in the original training quadrant during the probe trial. The histology scores did not significantly correlate with spatial latency and spatial and cued path lengths in block I (Table 2).

\section{Discussion}

Our studies reveal a behavioral dissociation among groups of rats with loss of cholinergic projections to the hippocampus alone versus loss of cholinergic projections to the hippocampus and neocortex. The specificity and extent of the lesion are discussed more fully elsewhere (Heckers et al., 1994).

\section{The effects of MSA lesions on spatial and cued learning}

We show, in the present study, that a nearly complete loss of cholinergic fibers in the dorsal and ventral hippocampus results in a decidedly small deficit in performance of a spatial navigation task. The MSA-injected group is not as efficient as the control group in locating the invisible platform in the initial phase of the spatial navigation task. This lower efficiency is evident in both longer escape latencies and path lengths. Asymptotic performance of the septal group, however, is virtually indistinguishable from controls for both escape latencies and path lengths. Furthermore, in the spatial probe trial, the septal group and controls perform similarly. These data suggest, therefore, that the MSA-lesioned rats are initially impaired on the spatial navigation task when compared to controls; both groups, however, are using spatial cues equally efficiently to guide their performance after $6 \mathrm{~d}$ of training.

Figure 9. Differences in the distribution of AChE-positive fibers in the target areas of the cholinergic basal forebrain neurons after injections of saline or $192 \mathrm{IgG}$ saporin: AChE-positive fibers in dorsal hippocampus (left column) and parietal cortex (right column) in a saline-treated rat $(A$, $B)$ and in rats after $192 \mathrm{IgG}$ saporin injections into the medial septal area $(C, D)$, the substantia innominata $(E$, $F)$, and the cerebral ventricle $(G$, H). Scale bar, $0.22 \mathrm{~mm}$. 
During the cued trials, the performance of the MSA-lesioned rats and controls is almost identical. Both groups of rats initially spend most of their time in the original training quadrant but quickly learn to locate the platform in another quadrant. The septal group, therefore, not only learns the spatial task as well (though not as quickly) as the controls, but also learns to transfer strategies to a cued task as quickly and accurately as controls.

These findings on the spatial task are in contrast to those reported following lesions of the MSA using ibotenate (Hagan et al., 1988) or electrolytic means (Miyamoto et al., 1987; Kelsey and Landry, 1988) and following damage to the fimbria-fornix, the pathway that connects the MSA and hippocampus (Nilsson et al., 1987; Eichenbaum et al., 1990). In these studies, MS $\Lambda$ lesions and fornix lesions result in significant and persistent impairments in the acquisition of the Morris spatial navigation task. Hagan et al. (1988) report that ibotenate-induced MSAlesioned rats exhibit spatial bias during probe trials and spend only $41 \%$ of their time in the training quadrant after $6 \mathrm{~d}$, which is substantially less than the $71 \%$ found in the IgG saporininduced MSA lesion group in the present study. Similar to our findings, rats with ibotenate-induced MSA lesions do not exhibit large differences in cued escape latencies when compared to controls.

The loss of cholinergic fibers in the hippocampus, as seen in the present study, is more substantial than losses previously reported following electrolytic lesions or local injections of ibotenate; spatial navigation impairments, however, are less dramatic. Despite the substantial loss of NGFr/ChAT-positive neurons in the MSA following the immunotoxin lesion, parvalbumin-positive presumably noncholinergic neurons in the MSA are preserved. This specificity is in contrast to findings following ibotenate, quisqualate, and fimbria-fornix lesions, which result in damage to noncholinergic MSA neurons as well as cholinergic neurons. Our results suggest that behavioral deficits seen in previous studies are associated with the loss of noncholinergic MSA neurons. Loss of ChAT-positive cells in the MSA, alone, could not account for these deficits.

\section{The effects of $n B M$ lesions on spatial and cued learning}

A virtually complete loss of cholinergic fibers in the frontal, temporal, parietal, and occipital isocortices with a mild to moderate loss of cholinergic fibers in the hippocampus and relative preservation of cholinergic fibers in the amygdala and entorhinal cortex is observed in the nBM lesion group. These decreases in cortical and hippocampal cholinergic fibers are associated with dramatic deficits in performance on the spatial navigation task. Both mean escape latencies and path lengths of the rats with $192 \mathrm{IgG}$ saporin injections to the $\mathrm{nBM}$ are significantly higher than those of the controls on almost all days of spatial testing. After $6 \mathrm{~d}$ of training, the nBM group is still not using spatial cues as efficiently as controls to guide spatial performance, as is cvident on the probe trial.

Overall, the nBM lesion group performs similarly to controls on the cued navigation task; mean escape latencies and path lengths are similar except on the first day of cued testing. One important difference between the performance of the $\mathrm{nBM}$ and control groups is that the nBM group spends considerably less time in the original spatial training quadrant than controls; in other words, the nBM group does not persevere in the training quadrant. Perhaps the nBM group is successfully learning the cued task because there is no interference from a bias developed in the spatial task. Similarly, quisqualate- and ibotenic acid- induced $\mathrm{nBM}$ lesions do not result in cued navigation deficits (Dunnett et al., 1987).

The severity of the spatial navigation deficit that is seen in the nBM group could be due to a number of factors: (1) a significant loss of cholinergic input to the cortex, (2) mild to moderate loss of cholinergic hippocampal inputs in addition to cortical losses, and/or (3) striatal damage. First, 192 IgG saporin-induced $\mathrm{nBM}$ lesions produce a significant loss of cholinergic fibers throughout the neocortical mantle greater than that seen following either ibotenic acid or quisqualate injections into the nBM (Heckers et al., 1994). This more extensive and more complete cholinergic loss could therefore lead to a more dramatic behavioral deficit. Second, the immunotoxin-induced $\mathrm{nBM}$ lesions affect neurons in the vertical limb of the diagonal band and result in mild to moderate decreases in dorsal and ventral cholinergic fibers in the hippocampus. Although the hippocampal loss alone does not produce a significant performance deficit, we cannot rule out the possibility that the combined loss of cortical and hippocampal projections in the nBM group is responsible for the severity of the deficit. Third, since the immunotoxin-induced nBM lesions decrease ChAT-positive striatal interneurons, it is possible that some of the behavioral differences noted are due to this loss. The loss of cholinergic interneurons of the striatum in the $\mathrm{nBM}$ group could be due to a reemergence of NGFr expression in response to local tissue damage (Gage et al., 1989). Ibotenate-induced striatal lesions, which affect both cholinergic and noncholinergic striatal neurons, reportedly impair spatial, as well as cued, navigation performance (Whishaw et al., 1987; Cook and Kesner, 1988; Packard et al., 1989). In the present study spatial, but not cued, navigation is altered, distinguishing this from the ibotenateinduced striatal lesion model and making the third alternative the least likely explanation. The present studies do not allow us to distinguish fully among the three aforementioned alternatives. However, we can say that a dramatic cortical cholinergic loss is a likely cause of the dramatic spatial learning and memory deficit.

It is considerably less likely that loss of noncholinergic nBM neurons is responsible for the dramatic behavioral deficits. The selectivity of the immunotoxin is supported by the fact that calbindin $\mathrm{D}_{28 \mathrm{~K}}$-positive neurons adjacent to the $\mathrm{nBM}$ are spared following the lesion. Furthermore, noradrenergic and dopaminergic fiber densities in the hippocampus and cortex are not changed following intraventricular immunotoxin injections, suggesting that fibers of passage through the basal forebrain are spared (Heckers et al., 1994).

It is interesting to note that in this immunotoxin lesion model, the $\mathrm{nBM}$ projection to amygdala is largely spared while the $\mathrm{nBM}$ projection to cortex is dramatically reduced. The preservation of cholinergic amygdala projections distinguishes this model from that produced by local injections of ibotenate into the $n B M$ (Boegman et al., 1992; Ileckers et al., 1994). Our data, therefore, suggest that loss of $\mathrm{nBM}$ projections to the amygdala are not necessary for the occurrence of spatial memory deficits.

\section{The effects of ventricular injections of immunotoxin on spatial and cued learning}

A virtually complete loss of the cholinergic projections to the hippocampus and isocortex, and relative sparing of the projections to amygdala, is observed in the ventricular group. The rats that have the most extensive cholinergic loss throughout the basal forebrain are the most severely impaired on behavioral 
measures; they are impaired on both the spatial and cued navigation task. The severity of the spatial deficit is similar to that described in a previous report (Nilsson et al., 1992). The higher mean escape latencies and longer path lengths on the spatial navigation task, and reduced spatial bias on the probe trial, all point to the fact that the ventricular group does not learn the spatial task as well as controls.

Our behavioral results must be interpreted in light of the fact that histological analyses reveal a significant loss of cerebellar Purkinje cells. Purkinje cells express the p 75 NGF receptor (Pioro and Cuello, 1988) and are affected by intraventricular IgG saporin injections (Heckers et al., 1994). We are not aware of studies of spatial and cued learning on the water maze following cerebellar lesions. Purkinje cell loss, however, does alter spatial spontaneous alternation behavior (Lalonde et al., 1987). Furthermore, the cerebellum plays a critical role in motor learning and classical conditioning learning (Steinmetz et al., 1992; see Watson, 1978, for review). Our data could therefore be interpreted as an inability of the rats with ventricular injections and consequent cerebellar damage to engage successfully in the appropriate motor sequence to direct movement toward the platform and get on it. The severity of the deficit in the ventricular group on the cued, as well as spatial, task indicates a performance deficit more dramatic than that previously noted from combined MSA/nBM lesions (Hepler et al., 1985), and Purkinje cell damage may be a contributing factor.

\section{Toward understanding the role of basal forebrain cholinergic systems in behavior}

Is the cholinergic basal forebrain sustem involved in movement and strategy selection? Carlton (1963) proposes that the central cholinergic system is involved in movement and strategy selection. Whishaw and collaborators have proposed that the cholinergic system is involved in the selection of strategies and movements that are a prerequisite for learning (Whishaw, 1985; Whishaw and Petrie, 1988). The behavioral data from the nBM and ventricular group would support these proposals. Neither group appears to employ a spatial strategy as efficiently as control or MSA-lesioned rats. As such our findings suggest that the nBM-cortical cholinergic pathway, and to a much lesser degree the septohippocampal pathway, may be involved in movement strategy selection in the spatial task. Neither pathway appears to be involved in appropriate strategy selections in the cued task.

Is the cholinergic system critical for spatial learning and memory? The significant correlations between cholinergic loss and navigation performance suggest that the more severe the cortical cholinergic damage, the more profound the effect on asymptotic spatial navigation performance. However, even a virtually complete cholinergic depletion to the cortex (with some loss to the hippocampus) does not completely abolish spatial learning and memory since all of the rats tested show improvement with repeated testing. The amount of correlation seen in the present study $(30-40 \%)$ is similar to that previously reported between cortical ChAT activity and swim quadrant analysis (Dunnett et al., 1987).

The navigation task is considered a reference memory task; the memory aspects of the task remain constant over trials because the platform remains in a fixed position in the pool (Morris, 1981). Our data suggest that MSA projections to hippocampus are not critical in this reference memory task. It is also possible, however, that this task may not be sensitive enough to detect the MSA lesion-induced deficits (Decker et al., 1992). Perhaps other memory-related tasks, such as a radial arm maze procedure, would be more sensitive in detecting a functional deficit, if one exists.

In conclusion, our studies show that a nearly total cholinergic denervation of the hippocampus is not sufficient to impair spatial memory in the Morris maze. In contrast, a combined loss of neocortical and some hippocampal cholinergic fibers leads to a substantial impairment of performance even when amygdaloid cholinergic afferents are largely spared. Although we cannot prove this definitively, our results suggest that neocortical cholinergic fibers are more critical than hippocampal cholinergic fibers for this spatial reference memory task.

\section{References}

Altar CA (1991) Nerve growth factor and the neostriatum. Prog Neuropsychopharmacol Biol Psychiatry 15:157-169.

Amaral DG, Kurz J (1985) An analysis of the origins of the cholinergic and noncholinergic septal projections to the hippocampal formation of the rat. J Comp Neurol 240:37-59.

Bartus RT, Dean RL III, Beer B, Lippa AS (1982) The cholinergic hypothesis of geriatric memory dysfunction. Science 217:408-417.

Boegman RJ, Cockhill J, Jhamandas K, Beninger RJ (1992) Excitotoxic lesions of rat basal forebrain: differential effects on choline acetyltransferase in the cortex and amygdala. Neuroscience 51:129-135.

Book AA, Wiley RG, Schweitzer JB (1992) Specificity of 192 IgGsaporin for NGF receptor-positive cholinergic basal forebrain neurons in the rat. Brain Res 590:350-355.

Brandeis R, Brandys Y, Yehuda S (1989) The use of the Morris water maze in the study of memory and learning. Int J Neurosci 48:29-69.

Carlton PL (1963) Cholinergic mechanisms in the control of behavior by the brain. Psychol Rev 70:19-39.

Connor DJ, Langlais PJ, Thal LJ (1991) Behavioral impairments after lesions of the nucleus basalis by ibotenic acid and quisqualic acid. Brain Res 555:84-90.

Cook D, Kesner RP (1988) Caudate nucleus and memory for egocentric localization. Behav Neural Biol 49:332-343.

Coyle JT, Schwarcz R (1983) The use of excitatory amino acids as selective neurotoxins. In: Handbook of chemical neuroanatomy, Vol I, Methods in chemical neuroanatomy (Bjorklund A, Hokfelt T, eds), pp 508-527. New York: Elsevier.

Coyle JT, Price DL, DeLong MR (1983) Alzheimer's disease: a disorder of cortical cholinergic neurons. Science 219:1184-1190.

Decker MW, Radek RJ, Majchrzak MJ, Anderson DJ (1992) Differential effects of medial septal lesions on spatial-memory tasks. Psychobiology 20:9-17.

Dekker AJAM, Connor DJ, Thal LJ (1991) The role of cholinergic projections from the nucleus basalis in memory. Neurosci Biobehav Rev 15:299-317.

Dunnett SB (1985) Comparative effects of cholinergic drugs and lesions of nucleus basalis or fimbria-fornix on delayed matching in rats. Psychopharmacology 87:357-363.

Dunnett SB, Whishaw IQ, Jones GH, Bunch ST (1987) Behavioral, biochemical and histochemical effects of different neurotoxic amino acids injected into nucleus basalis magnocellularis of rats. Neuroscience 20:653-669.

Dunnett SB, Everitt BJ, Robbins TW (1991) The basal forebraincortical cholinergic system: interpreting the functional consequences of excitotoxic lesions. Trends Ncurosci 11:494-501.

Durkin T (1989) Central cholinergic pathways and learning and memory processes: presynaptic aspects. J Comp Physiol 93:273-280.

Eichenbaum H, Stewart C, Morris RGM (1990) Hippocampal representation in place learning. $\mathrm{J}$ Neurosci 10:3531-3542.

Fibiger HC (1991) Cholinergic mechanisms in learning, memory and dementia: a review of recent evidence. Trends Neurosci 14:220-223.

Fraser KA, Poucet B, Partlow G, Herrmann T (1991) Role of the medial and lateral septum in a variable goal spatial problem solving task. Physiol Behav 50:739-744.

Freund TF (1989) GABAergic septohippocampal neurons contain parvalbumin. Brain Res 478:375-381.

Gage FH, Batchelor P, Chen KS, Chin D, Deputy S, Rosenberg MB, Higgins GA, Koh S, Fisher W, Bjorklund A (1989) NGF-receptor 
re-expression and NGF-mediated cholinergic neuronal hypertrophy in the damaged adult neostriatum. Neuron 2:1177-1184.

Hagan JJ, Salamone JD, Simpson J, Iversen SD, Morris RGM (1988) Place navigation in rats is impaired by lesions of medial septum and diagonal band but not nucleus basalis magnocellularis. Behav Brain Res 27:9-20.

Haroutunian V, Mantin R, Kanof PD (1990) Frontal cortex as the site of action of physostigmine in nbM-lesioned rats. J Behav 47: 203-206.

Heckers S, Ohtake T, Wiley RG, Lappi DA, Gcula C, Mcsulam M-M (1994) Complete and selective cholinergic denervation of rat neocortex and hippocampus but not amygdala by an immunotoxin against the P75 NGF receptor. J Neurosci 14:1271-1289.

Hepler DJ, Olton DS, Wenk GL, Coyle JT (1985) Lesions in nucleus basalis magnocellularis and medial septal area of rats produce qualitatively similar memory impairments. J Neurosci 5:866-873.

Hohmann CF, Antuono P, Coyle JT (1988) Basal forebrain cholinergic neurons and Alzheimer's disease. In: Handbook of psychopharmacology, Vol 20 (Iverson LL, Iverson SD, Snyder SH, eds). New York: Plenum.

Hsu SM, Raine L, Fanger H (1981) Use of avidin-biotin-peroxidase complex $(\mathrm{ABC})$ in immunoperoxidase techniques: a comparison between ABC and unlabeled antibody (PAP) procedures. J Histochem Cytochem 29:577-580.

Hurlbut BJ, Lubar JF, Switzer R, Dougherty J, Eisenstadt ML (1987) Basal forebrain infusion of $\mathrm{HC}-3$ in rats: maze learning deficits and neuropathology. Physiol Behav 39:381-393.

Ito $\mathrm{M}$ (1984) The cerebellum and motor control. New York: Raven.

Johnston MV, McKinney M, Coyle JT (1979) Evidence for a cholinergic projection to neocortex from neurons in the basal forebrain. Proc Natl Acad Sci USA 76:5392-5396.

Kelsey JE, Landry BA (1988) Medial septal lesions disrupt spatial mapping ability in rats. Behav Neurosci 102:289-293.

Kesner RP, Adelstein T, Crutcher KA (1987a) Rats with nucleus basalis magnocellularis lesions mimic mnemonic symptomatology observed in patients with dementia of the Alzheimer's type. Behav Neurosci 101:451-456.

Kesner RP, DiMattia BV, Crutcher KA (1987b) Evidence for neocortical involvement in reference memory. Behav Neural Biol 47:4053.

Lalonde R, Manseau M, Botez MI (1987) Delayed spontaneous alternation in Purkinje cell degeneration mutant mice. Neurosci Lett $80: 343-346$

Lewis PR, Shute CCD (1967) The cholinergic limbic system: projections to hippocampal formation, medial cortex, nuclei of the ascending cholinergic reticular system, and the subfornical organ and supraoptic crest. Brain 90:521-540.

Lodge M (1981) Magnitude scaling: quantitative measurement of opinions. Beverly Hills: Sage.

Mandel RJ, Thal LJ (1988) Physostigmine improves water maze performance following nucleus basalis magnocellularis lesions in rats. Psychopharmacology 96:421-425.

Mandel RJ, Gage FH, Thal LJ (1989) Spatial learning in rats: correlation with cortical choline acetyltransferase and improvement with NGF following NBM damage. Exp Neurol 104:208-217.

Markowska AL, Wenk GL, Olton DS (1990) Nucleus basalis magnocellularis and memory: differential effects of two neurotoxins. Behav Neural Biol 54:13-26.

McGurk SR, Hartgraves SL, Kelly PH, Gordon MN, Butcher LL (1987) Is ethylcholine mustard aziridinium ion a specific cholinergic neurotoxin? Neuroscience 22:215-224.

Messer WS Jr, Stibbe JR, Bohnett M (1991) Involvement of the septohippocampal cholinergic system in representational memory. Brain Res 564:66-72.

Mesulam M-M, Moran AM (1987) Cholinesterases within neurofibrillary tangles related to age and Alzheimer's disease. Ann Neurol 22:223-228.

Mesulam M-M, Mufson EF, Wainer BH, Levey AI (1983) Central cholinergic pathways in the rat: an overview based on an alternative nomenclature (Ch1-Ch6). Neuroscience 10:1185-1201.

M'Harzi M, Jarrard LE (1992) Effects of medial and lateral septal lesions on acquisition of a place and cue radial maze task. Behav Brain Res 49:159-165.

Miyamoto M, Kato J, Narumi S, Nagaoka A (1987) Characteristics of memory impairment following lesioning of the basal forebrain and medial septal nucleus in rats. Brain Res 419:19-31.
Morris RGM (1981) Spatial localization does not require the presence of local cues. Learn Motiv 12:239-260.

Murray CL, Fibiger HC (1985) Learning and memory deficits after lesions of the nucleus basalis magnocellularis: reversal by physostigmine. Neuroscience 14:1025-1032.

Murray CL, Fibiger HC (1986) Pilocarpine and physostigmine attenuate spatial memory impairments produced by lesions of the nucleus basalis magnocellularis. Behav Neurosci 100:23-32.

Nabeshima T, Ogawa S, Yamada K, Ishimaru H, Fuji K, Kameyama T, Fukuta T, Takeuchi R, Hayashi K (1991) Memory impairment and morphological changes in rats after continuous infusion of active fragment of anti-nerve growth factor-antibody. Res Commun Chem Pathol Pharmacol 74:141-152.

Nakamura S, Tani Y, Maezono Y, Ishihara T, Ohno T (1992) Learning deficits after unilateral AF64A lesions in the rat basal forebrain: role of cholinergic and noncholinergic systems. Pharmacol Biochem Behav 42:119-130.

Nilsson OG, Shapiro ML, Gage FH, Olton DS, Bjorklund A (1987) Spatial learning and memory following fimbria-fornix transection and grafting of fetal septal neurons to the hippocampus. Exp Brain Res 67:195-215.

Nilsson OG, Leanza G, Rosenblad C, Lappi DA, Wiley RG, Bjorklund A (1992) Spatial learning impairments in rats with selective immunolesion of the forebrain cholinergic system. Neuroreport 3:10051008.

Olton DS, Wenk GL (1987) Dementia: animal models of the cognitive impairments produced by degeneration of the basal forebrain cholinergic system. In: Psychopharmacology: the third generation of progress (Meltzer HY, ed), pp 941-953. New York: Raven.

Olton DS, Givens BS, Markowska AL, Shapiro M, Golski S (1991a) Mnemonic functions of the cholinergic septohippocampal system. In: Memory: organization and locus of change (Squire LR, Weinberger NM, Lynch G, McGaugh JL, eds), pp 250-272. New York: Oxford UP.

Olton DS, Markowska A, Voytko ML, Givens BS, Gorman L, Wenk G (1991b) Basal forebrain cholinergic system: a functional analysis. Adv Exp Med Biol 265:363-372.

Packard MG, Hirsh R, White NM (1989) Differential effects of fornix and caudate nucleus lesions on two radial maze tasks: evidence for multiple memory systems. J Neurosci 9:1465-1472.

Panula P, Revuelta AV, Cheney DL, Wu J-Y, Costa E (1984) An immunohistochemical study on the location of GABAergic neurons in rat septum. J Comp Neurol 222:69-80.

Paxinos G, Watson C (1986) The rat brain in stereotoxic coordinates. San Diego: Academic.

Perry EK, Tomlinson BE, Blessed G, Bergmann K, Gibson PH, Perry PH (1978) Correlation of cholinergic abnormalities with senile plaques and mental test scores in senile dementia. Br Med J 2:14571459.

Pioro EP, Cuello AC (1988) Purkinje cells of adult rat cerebellum express nerve growth factor receptor immunoreactivity: light microscopic observations. Brain Res 455:182-186.

Ridley RM, Murray TK, Johnson JA, Baker HF (1986) Learning impairment following lesion of the basal nucleus of Meynert in the marmoset: modification by cholinergic drugs. Brain Res 367:108116.

Robbins TW, Everitt BJ, Ryan CN, Marston HM, Jones GH, Page KJ (1989) Comparative effects of quisqualic and ibotenic acid-induced lesions of the substantia innominata and globus pallidus on the acquisition of a conditional visual discrimination: differential effects on cholinergic mechanisms. Neuroscience 28:337-352.

Rye DB, Wainer BH, Mesulam M-M, Mufson EJ, Saper CB (1984) Cortical projections arising from the basal forebrain: a study of cholinergic and noncholinergic components employing combined retrograde tracing and immunohistochemical localization of choline acetyltransferase. Neuroscience 13:627-643.

Saper CB (1984) Organization of cerebral cortical afferent systems in the rat I. Magnocellular basal nucleus. J Comp Neurol 222:313-342.

Steinmetz JE, Lavond DG, Ivkovich D, Logan CG, Thompson RF (1992) Disruption of classical eyelid conditioning after cerebellar lesions: damage to a memory trace system or a simple performance deficit? J Neurosci 12:4403-4426.

Stevens SS (1975) Psychophysics: introduction to its perceptual, neural, and social prospects. New York: Wiley.

Sweeney JE, Bachman E, Coyle JT (1990) The effects of different doses 
of galanthamine, a long acting AChE inhibitor in mice. Psychopharmacology 102:191-200.

Tago H, Kemura H, Macda T (1986) Visualization of detailed acetylcholinesterase fiber and neuron staining in rat brain by a sensitive histochemical procedure. J Histochem Cytochem 34:1431-1438.

Wainer BH, Mesulam M-M (1990) Ascending cholinergic pathways in the rat brain. In: Brain cholinergic systems (Steriade M, Biesold D, eds), pp 65-119. New York: Oxford UP.

Watson PJ (1978) Nonmotor functions of the cerebellum. Psychol Bull 85:944-967.

Wenk G, Cribbs B, McCall L (1984) Nucleus basalis magnocellularis: optimal coordinates for selective reduction of choline acetyltransferase in frontal neocortex by ibotenic acid injections. Exp Brain Res $56: 335-340$.

Whishaw IQ (1985) Cholinergic receptor blockade in the rat impairs locale but not taxon strategies for place navigation in a swimming pool. Behav Neurosci 99:979-1005.

Whishaw IQ, Petrie BF (1988) Cholinergic blockade in the rat impairs strategy selection but not learning and retention of nonspatial visual discrimination problems in a swimming pool. Behav Neurosci 102: 662-667.

Whishaw IQ, O'Connor WT, Dunnett SB (1985) Disruption of central cholinergic systems in the rat by basal forebrain lesions or atropine: effects on feeding, sensorimotor behaviour, locomotor activity and spatial navigation. Behav Brain Res 17:103-115.
Whishaw IQ, Mittleman G, Bunch ST, Dunnett SB (1987) Impairments in the acquisition, retention and selection of spatial navigation strategies after medial caudate-putamen lesions in rats. Behav Brain Res 24:125-138

Wiley RG (1992) Neural lesioning with ribosome-inactivating proteins: suicide transport and immunolesioning. Trends Neurosci 15: 285-290.

Wiley RG, Lappi DA (in press) Preparation of anti-neuronal immunotoxins for selective neural immunolesioning. In: Elsevier Neuroscience Protocols 1, in press. Amsterdam: Elsevier.

Wiley RG, Oeltmann TN, Lappi DA (1991) Immunolesioning: selective destruction of neurons using immunotoxin to rat NGF receptor. Brain Res 562:149-153.

Woolf NJ, Gould E, Butcher LL (1989) Nerve growth factor receptor is associated with cholinergic neurons of the basal forebrain but not the pontomesencephalon. Neuroscience 30:143-152.

Wozniak DF, Stewart GR, Finger S, Olney JW (1989) Comparison of behavioral effects of nucleus basalis magnocellularis lesions and somatosensory cortex ablation in the rat. Neuroscience 32:685-700.

Yan Q, Johnson EM Jr (1989) Immunohistochemical localization and biochemical characterization of nerve growth factor receptor in adult rat brain. J Comp Neurol 290:585-598. 